\title{
Research on Project Teaching and Flipped Classroom in Universities
}

\author{
Xiaojing Dong \\ Xijing University, Xi’an, Shaanxi, China \\ 664186437@qq.com
}

Keywords: Project Teaching, Flipped Classroom, Economy and Management Courses, Education Mode

\begin{abstract}
Project teaching is a new teaching mode, which is driven by task and oriented by project, which is becoming an effective means of practical teaching. As the emerging of new ideas and technologies,information technology and curriculum integration become increasingly advanced. Using network to transfer knowledge and invert knowledge,people achieve the purpose of the reallocation of classroom time. By integrating flipped classroom teaching into project teaching, students can reduce the teaching time of teachers and increase time to participate in the practice of project teaching, so as to compensate the shortage of classroom teaching time.Students learn the real work scene by watching the worker's live video before class to solve the difficult problem of imitated real work situation.At the same time,the students could collect the questions to ask teachers and teachers can concentrate on teaching key and difficulty and have time to encourage students to take part in discussions actively in class.
\end{abstract}

\section{The declination of relative items}

Project Teaching is used to on the students themselves to hand information over by teachers. Before a course in Economy and Management, students themselves have the responsibility to finish collecting information, design, implementation and final evaluation. Project is the main line, teachers are guides, students are the main body in educational procedure. Teachers and students complete the project together and make progress together.

Flipped Classroom is to break the traditional mode of learning homework in class and create a new classroom mode for students to practice and consolidate in class. The direct result of its operation is that students focus on discussing, communicating, and cooperating in solving problems in each BYOD(Bring Your Own Development with its own equipment learning) class. ${ }^{[1]}$

The traditional teaching mode in our country, is emphasized 'knowledge-based', and is the major educational procedure in class, at colleges and universities by teachers before students enter into practice stage. This kind of teaching mode is led to make the students lack the perceptual understanding of the research object in the classroom, and feel that the theoretical knowledge is abstract and difficult to understand, and lose interest in learning. When you have the opportunity to have a perceptual understanding of the subject, you forget a lot of theoretical knowledge. 


\section{The present situation of 'project teaching+Flipped Classroom'}

It is very difficult for students to form systematic comprehensive skills under the correct theoretical guidance, and it is very difficult to mobilize students 'initiative, participation and cooperation in the learning process, thus affecting the improvement of students' professional skills. ${ }^{[2]}$ The project teaching method attempts to combine theory and practice organically by implementing a series of complete teaching projects. It is a task-oriented teaching activity, with the development of students 'professional skills as its primary task.

Compared with the traditional teaching way, the project type teaching method in the education idea, teaching goal, teaching environment, teaching process and teaching methods have changed a lot, it is no longer with the teacher as the center, emphasis on students' autonomous learning. But the project type teaching method usually need more teaching time, to realize the efficient use of class time, we should consider whether will be the first step in learning process - in extra-curricular knowledge transfer process? In today's rapid development of information technology such as multimedia, computer, Internet, under the support of the transmission of information is becoming more and more convenient and easy, can realize the students before class, using modern teaching means to understand the contents of the need to learn in the class time can be used for students to absorb knowledge internalization.

In the classroom, teachers mainly play the role of consultation and coordinators, and teachers and students can make a deeper and detailed study of the knowledge points through collaborative interaction in the classroom. ${ }^{[3]}$ This kind of study way to flip the traditional classroom teaching, classroom, doing his homework way under the so called flipped class (inverted classroom), flip the classroom is very suitable for use in the project type teaching a kind of teaching method.

By combining theory with practice teaching, project-based teaching method can mobilize and explore students' creative potential, which changes the pattern of separation of theoretical teaching and practice teaching in traditional teaching. ${ }^{[4]}$ Under the guidance of constructivism, project teaching method in the form of a project, from the traditional subject system to integrate the teaching content, to master the knowledge content is divided into several relatively independent teaching project, each teaching project has certain tasks. In the course of teaching, teachers should first decompose the project and make appropriate demonstration, and then the students should work together to complete the project tasks within a limited time.

Students directly involved in the process of project implementation, understanding every part of the project, and the results after the completion of the project summary evaluation, master including knowledge, grasp the key difficulties in the process of project implementation, finally realizes the 'learning by doing' approach to learning.

Project Teaching Method is a lot of typical characteristics of practicality, experiential, it pays attention to is not the result of project finally achieved, but to make students obtain the knowledge, skills, through the implementation of specific projects and the methods to solve the problem, to complete the project in the process of cultivating students' work sense of responsibility and team cooperation ability, cultivate students' ability of interdisciplinary, interdisciplinary complex work, cultivate students' ability of knowledge to deepen and expand. Project teaching method in the 
teaching project from the engineering practice, the choice of every project is different from other projects of learning objectives, knowledge point of multiple connected to each other, and influence each other can be dealt with through systematic teaching will fuse into a project.

In the process of teaching design, students should be represented as the center of the teaching organization. Teachers are not simply teaching knowledge in the classroom. ${ }^{[5]}$

Students are no longer passively learning the fixed process designed by teachers. When teachers design the teaching content of the project, we must give full consideration to the students' interest in learning, give full play to the students' initiative, enthusiasm and creativity, to ensure every student to vital task to participate in the completion of the process. Students to complete the task in the process of participating in the design of the learning process, through continuous to find and solve the problem in order to get more knowledge and widen the vision, the teacher must at the right time problems give proper guidance to students. Project teaching method by making every student directly involved in the implementation of the project, to stimulate students' curiosity, to attract the attention of students, strengthen their initiative in learning, students to complete the project tasks to implement on a large number of new knowledge, make easier to understand and memory of knowledge, keep for longer periods of time, so as to improve teaching efficiency..

\section{The application of Flipped Classroom in Project Teaching}

\subsection{Necessity}

The problems involved in each project in the Project Teaching are characterized by comprehensiveness and openness, regardless of their size. Comprehensiveness refers to the theoretical knowledge and practice of project-based teaching and learning, and the implementation of each project embraces a variety of knowledge and skills. Openness, means it is not limited to books, also is not limited to from a certain perspective, it involves problems are very practical, changing development, can be analyzed from various angles. In addition,Project Teaching focusing on the combination of theory and practice at the same time, also do not relax the grasp of the basic theory, each project must consider when choosing the rationality of the selected topic and the order before the preparation work of knowledge. It is a good choice to integrate the flipped classroom teaching concept into the project-based teaching task in order to complete the teaching task of the project-type teaching.

First of all, flipped classroom is a very practical teaching method, which can use all kinds of advanced teaching methods to enhance the teaching effect. For more easily understood knowledge points, students can be taught by teaching courseware taught by teachers.

For the more abstract and difficult to understand or describe the knowledge points, you can consider using $2 \mathrm{~d}$ or $3 \mathrm{~d}$ animation techniques to make it vivid,

Concrete and figuratively displayed; To the project type teaching is not easy to imitate the field work of scene, a three-dimensional, full range can through the video show, this not only stimulated the students' interest in learning, but also can give a person with three-dimensional thinking, improve the people's imagination. 
Second, the project type teaching in the teaching contents, course large capacity, in the traditional classroom teachers to explain clearly every project involves all the knowledge of can make insufficient class time, teachers need to select teaching content as much as possible to ensure that students before the class classroom practice operation time. And turn into the classroom project teaching greatly extended the student's study time, students can choose according to oneself circumstance and arrange learning content, and sharing of network resources but also provides students with a large number of sources of knowledge, students can choose according to their own actual situation on the network reading relevant information, to the already familiar with knowledge don't have to spend time to learn, as long as read his not clear knowledge. Rather than as a traditional classroom, all students must learn in the classroom the teacher prepared the teaching content and teaching arrangement does not consider the specific students familiar with have certain knowledge or never heard of a concept.

Thirdly, the integration of project-based teaching in flipped classroom will break the limitation of traditional teaching methods for students' learning space and learning schedule. Students can choose in their own think comfortable environment of teaching courseware, according to their own mastery of knowledge and understanding of knowledge is to adjust the schedule progress, according to its own state flexibility to learn at their own place and time allocation, improve the learning efficiency. To use flip save out of classroom time classroom teaching mode, can be used for students to participate in the project practice, in the process of practice can watch video theory problems before class and class of operation problems in the practice of directly discuss with classmates and teachers, increase the students and teachers face to face communication time. This kind of productive face-to-face interaction learning and hands-on project practice is the most important application value of flipped classroom in project-based teaching.

\subsection{Feasibility}

First of all, with the development of network technology and computer technology, advanced information technology and software support realize the teaching courseware through network transmission. In under the guidance of the teaching goal, can use VC, high-level programming languages such as JAVA, and general multimedia tools such as Powerpoint, Flash, Authorware processing to the classroom teaching content, make the teacher in the mastery of knowledge points needed to explain at the same time be able to image, video and other material related to the teaching content is included in the courseware, form the illustrated digital instructional resource, so that the students can get the situation of experience teaching program, stimulate students' interest in learning. Students of all relevant majors can use the Internet to enjoy the courseware resources made by teachers.

Second, teaching methods are changing with each passing day to make the teaching concept, teaching students as the core, using the Internet can provide different students with suitable to the characteristics of learning materials, strategies and methods, use of digital multimedia technology to teaching content vividly students now right in front, can also be inserted into the appropriate music, animation, to produce a strong appeal, 
The network is no longer the auxiliary tool of teachers' explanation, but becomes an important means to convey the teaching content, and becomes an important cognitive tool for students to explore, discover and learn. Universities can make your own video materials uploaded to the Internet, video submissions can also download other colleges, through the network platform of the integration of direct information and teaching resource sharing is realized.

At the end, the project type teaching to students through direct participation in the implementation of the project to complete mastery of relevant knowledge, need to know before participating in the concrete implementation of the specific steps of the project, it is better to visit the implementation of the actual project site,but for most students, this is difficult to achieve. Flip the classroom can solve this problem, to some extent by a video video directly to the students represent the real work environment, equipment structure, working process, it can make students understand the content of the project type teaching directly before the class, saved the classroom teachers explain time.

\section{Conclusion}

Project-based teaching enables students to experience the application of knowledge and skills in the classroom and to explore and realize the construction and transfer of knowledge. However, because the teaching content of project type teaching is more than traditional classroom teaching, it makes class time very tense. Turn into the classroom project teaching make full use of the modern information environment, rich network resources, can make students in the class teaching courseware based on the autonomous learning completing the process of imparting knowledge and skills.

\section{Acknowledgement}

It is from the item' How to make students progress in Economy and Management Courses, which is a task from Xijing University(Xijing University support GZJGGH1703).

\section{References}

[1] Burden, P.( 1982) .Implications of teacher career develop-ment: New roles for teachers, administrators and professors[J]. Actionin Teacher Education, 4( 4) : $21-25$.

[2] Assessing students' changing perceptions of higher education:research in higher education,Bitzer,E.M.[J].South African Journal of Higher Education,2003, Vol.17 (3), pp. 164-177.

[3] Learning in academia is more than academic learning: action research in academic practice for and with medicalacademics, Chris Trevitt[J]. Educational Action Research, 2008,Vol.16 (4), pp.495515.

[4] Crouch,H.,Mazur,E.(2001). Peer instruction: Ten years of experience and results[J]. American journal of physics, 69(9): $970-977$.

[5] Inverting the Linear Algebra Classroom. Robert Talbert. http://prezi.com/ dzorbkpy6tam/ inverting-thelinear-algebra-classroom. 